\title{
Correction to: A Composite Measure of Gambling Exposure: Availability, Accessibility or Both?
}

\author{
S. M. Ofori Dei ${ }^{1}$ - D. R. Christensen ${ }^{1,4}$ (D) O. A. Awosoga ${ }^{1}$ B. K. Lee ${ }^{1} \cdot$ A. C. Jackson ${ }^{2,3,4,5}$ \\ Published online: 9 April 2021 \\ ○) Springer Science+Business Media, LLC, part of Springer Nature 2021
}

\section{Correction to: Journal of Gambling Studies https://doi.org/10.1007/s10899-020-09985-8}

The original version of this article unfortunately contained a mistake. The subheading "Composite Eeasure of Exposure" should read as "Composite Measure of Exposure". The original article has been corrected.

Publisher's Note Springer Nature remains neutral with regard to jurisdictional claims in published maps and institutional affiliations.

The original article can be found online at https://doi.org/10.1007/s10899-020-09985-8.

\section{R. Christensen}

darren.christensen@uleth.ca

1 Faculty of Health Sciences, University of Lethbridge, 4401 University Drive, Lethbridge, AB T1K 3M4, Canada

2 Australian Centre for Heart Health, North Melbourne, Australia

3 Faculty of Health, Deakin University, North Melbourne, Australia

4 Melbourne Graduate School of Education, University of Melbourne, Melbourne, Australia

5 Centre on Behavioral Health, University of Hong Kong, Hong Kong, China 